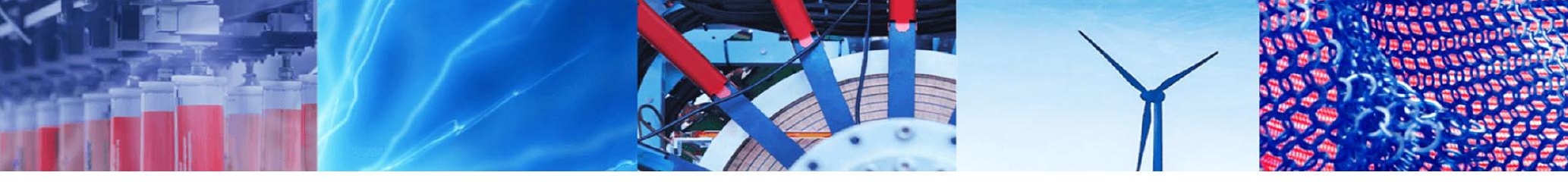

Research Article

\title{
Development of a saprophytic fungal inoculum for the biodegradation of sub-bituminous coal
}

\author{
Imade Yolanda Nsa ${ }^{1}$ (D) Busayo Tosin Akinyemi ${ }^{1} \cdot$ Maryam Bello-Akinosho ${ }^{2} \cdot$ Simon Nnamdi Ezechukwu $^{1}$. \\ Tomisin Bridget Bayode ${ }^{1} \cdot$ Eric Egbe Igbinigie $^{3} \cdot$ Rasheed Adegbola Adeleke ${ }^{2,4}$
}

Received: 15 May 2021 / Accepted: 13 December 2021

Published online: 12 January 2022

(c) The Author(s) 2022 OPEN

\begin{abstract}
The rhizospheres of the weeds Ageratum conyzoides, Axonopus compressus, Emilia coccinea, Synedrella nodiflora, Urena lobata and Sida acuta from a sub-bituminous coal mining site and a control site, without coal discards, were screened for new fungi with ability to degrade sub-bituminous coal in the laboratory. The isolates were identified by cultural and molecular methods. Seventeen out of the sixty-one fungal isolates tested could utilize sub-bituminous coal as an energy source. Upon further evaluation, only seven of these were promising candidates for coal biodegradation, and they were assayed for their biosolubilization and depolymerization activities to determine their mechanisms of coal biodegradation. Based on the accumulation of humic acid (HA), which is the marker for biosolubilization, Mucor circinelloides and Aspergillus tubingensis were the most active. On the other hand, Cunninghamella bertholletiae, Simplicillium subtropicum, Penicillium daleae and Trichoderma koningiopsis were the highest producers of fulvic acid (FA), the indicator of depolymerization. Purpureocillium lilacinum produced the lowest yields of both HA and FA compared to the other six coal-degrading candidates. The presence of laccase in Trichoderma koningiopsis, Penicillium daleae and Simplicillium subtropicum suggests a role for this enzyme in the enhancement of the coal biodegradation process. However, the inability to amplify the laccase gene in Cunninghamella bertholletiae indicates that another enzyme probably aids its coal bioconversion. The current investigation highlights the potentials of these strains in harnessing biotechnological processes of sub-bituminous coal conversion into value-added products, which could be extended to the bioremediation of coal-polluted soils. The fungi with the highest coal bioconversion capabilities belonged to Ascomycota and Zygomycota and were found in the rhizospheres of the weeds Emilia coccinea, Ageratum conyzoides and Axonopus compressus.
\end{abstract}

Keywords Sub-bituminous coal · Fungi · Humic acid · Fulvic acid · Biosolubilization depolymerization

Supplementary Information The online version contains supplementary material available at https://doi.org/10.1007/s42452-021-

04925-6.

$\triangle$ Imade Yolanda Nsa, insa@unilag.edu.ng | ${ }^{1}$ Department of Microbiology, Faculty of Science, University of Lagos, Lagos,

Nigeria. ${ }^{2}$ Microbiology and Environmental Biotechnology Research Group, Agricultural Research Council - Soil Climate and Water, Pretoria, South Africa. ${ }^{3}$ Assured Turnkey Solutions, Randburg, South Africa. ${ }^{4}$ Unit for Environment Science and Management, North-West University, Potchefstroom Campus, Potchefstroom, South Africa.

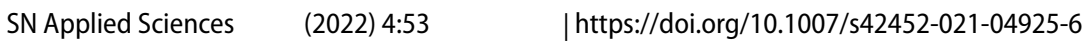




\section{Introduction}

Coal mining has considerable impact on the environment since coal production, its utility and disposal cause significant agricultural and environmental concerns [1-4]. The environmental impact includes loss of vegetation as well as the replacement of valuable indigenous agricultural plant species by grasses and other weeds [5-8]. Sub-bituminous coal is a lowerranked coal in calorific terms $(8500-13,000 \mathrm{Btu} / \mathrm{lb})$ in comparison with anthracite (13,000-15,000 Btu/lb) and bituminous coal $(11,000-15,000 \mathrm{Btu} / \mathrm{lb})$ but higher than lignite (4000-8.300,000 Btu/lb) [9-11]. Sub-bituminous coal constitutes a significant percentage of Nigeria's coal reserves, and it is located in both the Lower and Upper Benue Trough as well as in many parts of Enugu [12-14]. The subsequent abandonment of the Enugu mines and the indiscriminate disposal of coal discards led to environmental degradation in the area as evidenced by the loss of agricultural species [15].

Microbial coal conversion can be executed through any of these bioprocesses: depolymerization, decolorization, liquefaction and solubilization. Depolymerization is defined as the catabolic reduction in higher-molecularmass coal to smaller fractions which could be accompanied by a loss of chromophores, whereas decolorization (bleaching) is the loss of chromophores without any change in the molecular size $[16,17]$. Liquefaction is defined as a change of physical state (solid to liquid) and should not be confused with solubilization, which is the dissolution of all or part of the coal molecule [18]. Coal-degrading microbes naturally occur in coal dumpsites where coal bioconversion has been shown to occur in situ. A deuteromycete, Neosartorya fischeri isolated from the rhizosphere of the grass, Cynodon dactylon has been reported to degrade lignite, a low-grade coal [19-21]. A screen of the root zones of plants from a subbituminous coal dumpsite identified coal-active fungi belonging to Ascomycetes, Zygomycetes, Sordariomycetes and Leotiomycetes [22].

There is evidence that fungal degradation of coal waste permits its transformation into fuels or humic substances, which play important roles in carbon recycling as well as improvement of physical and chemical quality of soil structure. These invariably promote plant growth and development $[21,23-26]$. Humic acid (HA) is a product of coal solubilization, and the fungi known to break it down are principally Ascomycetes and Basidiomycetes [27]. Humic acid is a heterogeneous macromolecule with a molecular weight of $10,000-100,000 \mathrm{Da}$. It is characteristically dark brown to black in color with solubility at high $\mathrm{pH}$ and precipitation at low $\mathrm{pH}$ [28-30]. On the other hand, fulvic acid (FA) is a yellow product of depolymerization of $\mathrm{HA}$. It solubilizes at any given $\mathrm{pH}$ and has a lower molecular weight of 1000-10,000 Da, which is lower than that of HA. It is formed by the cleavage of bonds inside the coal macromolecule $[28,30,31]$.

It has been proposed that the biosolubilization and depolymerization of lignite could involve either microbial formation of alkaline substances or activities of ligninolytic enzymes or a combination of both [32]. Furthermore, the oxidative action of ligninolytic enzyme, laccase, played a key role in N. fischeri ECCN84 metabolizing waste low-rank coal and extracting carbon for growth and proliferation [20]. The various classes of ligninolytic enzymes reported in lignocellulosic waste degradation include laccases, lignin peroxidases, versatile peroxidase and manganese peroxidases [33].

Fungal mediated degradation of sub-bituminous coal [34-36] and the bacterial degradation of bituminous coal discards have been documented [37]. Furthermore, the previous investigation by Nsa et al., [22] focused on the identification of rhizospheric fungi from only polluted soils of an abandoned sub-bituminous coal mine site by culture techniques and microscopy. This present study has been expanded to include (1) screening of the rhizospheres of plants (weeds) growing on the coal-polluted site as well as a control site for coal-degrading fungi (2) determining the sub-bituminous coal utilization capabilities of these isolates in the laboratory (3) molecular identification of the isolates (4) potential functional attributes of the fungal isolates and (5) determining the presence of ligninolytic enzymes in the species with coal bioconversion capabilities.

\section{Materials and methods}

\subsection{Source of soil and coal samples}

Soil samples were obtained from the rhizospheres $(R)$ of weeds growing on a coal dump site (IZ; Incident Zone) by a defunct mine, and controls were obtained from a site free of coal discards (CZ; Control Zone) [38]. The rhizospheres that were screened for fungi include Emilia coccinea (RIZ3, $\mathrm{RCZ2B}$ ), Axonopus compressus (RIZ4 and RCZ2D), Synedrella nodiflora (RIZ5 and RCZ1D), Ageratum conyzoides (RIZ 8B, RIZ9, RIZ10 and RCZ2A), Sida acuta (RIZ11) and Urena lobata (RCZ2C).

Sub-bituminous coal samples were obtained from the defunct Ogbete mine, Udi, Local Government Area (LGA) of Enugu State, Nigeria. The coal samples were collected using hand gloves and transported on ice to the laboratory where they were pulverized using a CBR mold and rammer $(4.5 \mathrm{~kg})$. 


\subsection{Isolation and enumeration of soil fungi}

\subsubsection{Isolation of pure cultures}

One gram of soil sourced from each of the RIZ and RCZ samples was placed into its respective bottle holding 9-ml sterile distilled water and shaken for homogenization. For each sample, tenfold serial dilutions up to $10^{-6}$ dilutions were made. Aliquots of $1 \mathrm{ml}$ were taken from the $10^{-3}$ and $10^{-6}$ dilutions of each of the ten soil samples and plated on Sabouraud Dextrose Agar (SDA) (Rapid Labs AZ, USA) and Potato Dextrose Agar (PDA) (HiMedia Mumbai, India) using the pour plate technique. All plates were incubated at $25^{\circ} \mathrm{C}$ on both SDA and PDA for 5-7 days. Plates with luxuriant growth were chosen from the mixed culture plates for screening. Individual colonies were selected after two rounds of sub-culturing on SDA plates to obtain pure cultures. Conidial suspensions were made for each isolate, and $100 \mu$ volume was plated. The agar plates were incubated at $25^{\circ} \mathrm{C}$ for $5-7$ days, and the pure cultures of the isolates were stored on slants at $4{ }^{\circ} \mathrm{C}$ and $-20^{\circ} \mathrm{C}$ for future use.

\subsection{Test for coal activity}

All the strains obtained from the screen were checked for coal utilization. Coal activity of each pure isolate was tested on solid media, coal agar plate (CAP) and in liquid media, coal broth (CB).

Coal agar plate (CAP) The pure cultures of the individual fungi were inoculated on sub-bituminous coal agar plates, water agar plates and SDA plates for $5-7$ days at $25^{\circ} \mathrm{C}$. The coal agar medium consisted of $20 \mathrm{~g}$ of pulverized coal and $15 \mathrm{~g}$ agar-agar per liter of distilled water $[22,39]$. Water agar plates (WAP) made of $15 \mathrm{~g}$ of agar-agar in $1 \mathrm{~L}$ of distilled water served as the negative control, while SDA plates served as the positive control.

Coal broth $(C B)$ Coal activity was also tested on a coal broth containing Minimal Salts Medium (MSM) and coal. Twenty grams of pulverized coal was added to 1 I of MSM, heated, and stirred for homogenization; $100 \mathrm{ml}$ of the medium was dispensed into $250-\mathrm{ml}$ conical flasks and autoclaved at $121{ }^{\circ} \mathrm{C}$ at $15 \mathrm{psi}$ for $15 \mathrm{~min}$. On cooling, same-age mycelia obtained from each of the 61 isolates were inoculated into $\mathrm{CB}$ for 7 days at $25^{\circ} \mathrm{C}$ without shaking. The positive control medium was composed of MSM and glucose (Sigma-Aldrich, Taufkirchen, Germany), at a concentration of $0.056 \mathrm{M}$. The negative control medium comprised of MSM only. Selection of strains with coal utilizing capabilities was based on growth on coal agar, a tuft of mycelial mass at the base of the CB flask or by turbidity [22].

\subsection{Biosolubilization assay}

\subsubsection{Coal pre-treatment}

For the biosolubilization testing, the 17 strains that grew both on CAP and in CB were used. To remove excess phenolic compounds known to affect solubilization rates, sterile pulverized sub-bituminous coal was pre-treated with nitric acid $\left(\mathrm{HNO}_{3}\right.$ ) (HiMedia, Mumbai, India). One gram of coal was added to a flask containing $50 \mathrm{ml}$ of $30 \%$ $\mathrm{HNO}_{3}(1: 50 \mathrm{w} / \mathrm{v})$ and incubated at room temperature with shaking for $48 \mathrm{~h}[40,41]$. The pre-treated coal was rinsed with sterile distilled water $\left(\mathrm{dH}_{2} \mathrm{O}\right)$ until a clear rinsate of $\mathrm{pH}>5$ was obtained, and then dried in an oven at $40^{\circ} \mathrm{C}$. The medium for the biosolubilization assay was Czapek Dox Broth containing sucrose (HiMedia, Mumbai, India) as the sole carbon source, while sodium nitrate (HiMedia, Mumbai, India) served as the sole nitrogen source [41]. The pre-treated coal was added to the Czapek Dox broth at a concentration of $2.5 \%$.

\subsubsection{Preparation and testing of fungal strains}

Each fungal inoculum was prepared by rinsing 5-day old fungal mats (10 $\mathrm{mm}$ in diameter) from SDA plates with sterile $\mathrm{dH}_{2} \mathrm{O}$. Every mat was re-suspended in 2-ml sterile $\mathrm{dH}_{2} \mathrm{O}$, and the resulting fungal concentrate was inoculated into 100-ml Czapek Dox Broth in a 250-ml Schott bottles. Samples were incubated at $28^{\circ} \mathrm{C}$ for 5 days with shaking at $150 \mathrm{rpm}$. The formation of fungal biomass was monitored visually. The $\mathrm{pH}$ measurements of the media were obtained, and the HA and FA concentrations in the culture supernatants were analyzed by spectrophotometry as described by Fakoussa and Frost [42]. The uninoculated flasks containing only the media served as controls. After a 5-day incubation period, either a brown-colored appearance or subsequent clarification of the broth indicated culture activity.

\subsubsection{Analysis of HA standard measurements}

To determine the extent of biosolubilization activity, HA production was measured. The resultant cultures from above were first filtered using a 36- $\mu \mathrm{m}$ mesh. Humic acidlike substances (HS) were extracted and analyzed using a method adapted from Janoš [30]. Humic acid in the filtrate was precipitated by reducing the $\mathrm{pH}$ to less than 1 using a minimal volume of concentrated $\mathrm{HCl}(32 \%)$, while the filtrate was separated and kept for FA analysis. For each culture, the pellet, containing $\mathrm{HA}$, was re-suspended in 10-ml volume of $0.1 \mathrm{M} \mathrm{NaOH}$ and centrifuged using an Eppendorf 5415D desktop centrifuge, at $3220 \times \mathrm{g}$ for $90 \mathrm{~min}$ at $10^{\circ} \mathrm{C}$ to compact undissolved substances in a pellet. The 
pellet was discarded, while the absorbance values of the supernatants were determined by spectrophotometry at a wavelength of $450 \mathrm{~nm}\left(\mathrm{~A}_{450}\right)$ for $\mathrm{HA}$ concentrations [42].

Humic-like substances in the supernatant were quantified by interpolation from standard curves for $\mathrm{HA}$ at $\left(\mathrm{A}_{450}\right)$ [42]. This was made by making five concentrations $(40,80$, $120,160,200 \mathrm{mg} / \mathrm{L}$ ) of HA standards (International Humic Substance Society, Denver, CO, USA) and plotted against their respective absorbance values. The absorbance values of the HA in the media were read, and the concentration gradient was calculated from the straight-line equation $(y=0.0082 x)$ to determine the level of biosolubilization.

\subsubsection{Depolymerization test}

Fulvic acid standard measurements were analyzed to determine depolymerization activity. For each sample, the saved filtrate from the biosolubilization assay was allowed to stand for $1 \mathrm{~h}$ before centrifugation under the same conditions as conducted for HA. The supernatant was decanted, and analyzed by spectrophotometry at a wavelength of $280 \mathrm{~nm}$ for FA. The FA analysis was done by interpolation from standard curves for fulvic acid $[42,43]$.

\subsection{Molecular identification of fungal isolates}

\subsubsection{Fungal DNA isolation}

Genomic DNA was extracted from the fungal isolates using Zymo Research Quick-DNA Fungal/Bacterial Miniprep ${ }^{\mathrm{TM}}$ extraction kit (CA, USA) according to the manufacturer's instructions.

\subsubsection{Amplification of internal transcribed spacer (ITS) regions of fungal isolates}

Polymerase chain reaction (PCR) of the extracted genomic DNA from the 61 isolates was done in a Bio-Rad T100 ${ }^{\mathrm{TM}} \mathrm{PCR}$ thermocycler (Bio-Rad, Hercules, CA, USA). Each 25- $\mu$ l reaction mix consisted of $12.5 \mu$ l of One Taq ${ }^{\circledR} 2 \times$ Master Mix with Standard Buffer (New England BioLabs, MA, USA), $50 \mathrm{ng} /$ $\mu$ of DNA template, $0.2 \mu \mathrm{M}$ each of forward (ITS1-F: $5^{\prime}$-TCC GTA GGT GAA CCT GCG G-3') and reverse (ITS4-R: 5'-TCC TCC GCTTATTGA TAT GC-3') primers [44] and sterile nuclease-free water. Reaction mixture without DNA template was used as the negative control. The PCR conditions were as follows: initial denaturation step, $94^{\circ} \mathrm{C}$ for $30 \mathrm{~s}, 35$ cycles of $30 \mathrm{~s}$ denaturation at $94^{\circ} \mathrm{C}$, annealing at $55^{\circ} \mathrm{C}$ for $60 \mathrm{~s}$, elongation at $68^{\circ} \mathrm{C}$ for $60 \mathrm{~s}$, a final elongation step at $68^{\circ} \mathrm{C}$ for $5 \mathrm{~min}$. The Quick-Load Purple $1 \mathrm{~kb}$ DNA ladder (New England BioLabs, MA, USA) and the amplicons were loaded on a $1 \%$ ethidium bromide agarose gel that was run at $60 \mathrm{~V}$ for $1 \mathrm{~h}$ with
Bio-Rad ${ }^{\oplus}$ PowerPac ${ }^{\mathrm{TM}}$ Basic Power Supply and visualized with Bio-Rad Gel Doc ${ }^{\text {TM }}$ EZ Imager (Bio-Rad, Hercules, CA, USA).

\subsubsection{DNA sequencing and phylogenetic analyses of isolates}

The amplicons were sequenced at Inqaba Biotechnical Industries (Pty) Ltd., Pretoria, South Africa. The sequences were checked for quality and assembled using BioEdit (version 7.6.2.1) Sequence Alignment Editor [45]. The consensus sequence obtained for each was compared to the GenBank nucleotide data library using the Basic Local Alignment Search Tool, BLAST software [46] at the National Centre for Biotechnology Information (NCBI (http://www.ncbi.nlm.nih. gov). Sequence homology was used for preliminary identification of the isolates, using the BLAST. Mothur software pipeline was used to cluster sequences of the 17 isolates (that were active on coal) into operational taxonomic units (OTUs) at sequence similarity of $\geq 97 \%$. Phylogenetic reconstruction of the sequences was done by multiple sequence alignments of the OTU sequences with closely related sequences in the Genbank as well as an outgroup sequence of Gigaspora margarita. The sequence alignment was done on MAFFT [47] and aligned multiple sequences were edited with evolutionary history among them inferred using the Neighbor-Joining method [48]. The phylogenetic relationship established was constructed in MEGA X [49] using maximum composite likelihood model [50] with 1000 bootstrap replications [51].

\subsubsection{Identification of laccase gene}

Amplification of the laccase gene was done using primer sets LacF (5'-CAYTggCAYggNTTYTTYCA-3'), LacR (5'-TgRAA RTCDATRTgRCARTg-3') [52, 53]. Genomic DNA extracted from each fungus with positive coal activity served as a template in the PCR. The reaction mix was made of $2 \mu \mathrm{l}$ of template DNA, 0.5 $\mu \mathrm{l}$ LacF Primer $(10 \mu \mathrm{M}), 0.5 \mu \mathrm{l}$ LacR Primer $(10 \mu \mathrm{M}), 12.5 \mu \mathrm{l}$ of One Taq $2 \times$ Master Mix and $9.5 \mu$ sterile distilled water in $25 \mu$ total volume. PCR mix without DNA was used as a negative control for each PCR run. The PCR run conditions in the thermal cycler (Bio-Rad $\mathrm{T}^{100} \mathrm{O}^{\mathrm{TM}}$ ) were initial denaturation of $94^{\circ} \mathrm{C}$ for $30 \mathrm{~s}, 35$ cycles of denaturation (94 ${ }^{\circ} \mathrm{C}$ for $\left.30 \mathrm{~s}\right)$, annealing $\left(55^{\circ} \mathrm{C}\right.$ for $\left.60 \mathrm{~s}\right)$, extension $\left(68^{\circ} \mathrm{C}\right.$ for $60 \mathrm{~s}$ ) and then by a final extension of $68^{\circ} \mathrm{C}$ for $5 \mathrm{~min}$. PCR products were run on a $1 \%$ agarose gel and viewed on the Bio-Rad Gel Imager. 


\section{Results and discussion}

\subsection{Determination of fungal isolates}

The mixed cultures of the initial fungal screen of the rhizosphere samples on PDA (Fig. S1) yielded a total of 61 unique isolates ( 34 and 27 from RIZ and RCZ respectively) (Table 1; Fig. S2). They were identified as belonging to the genera Aspergillus, Trichoderma, Fusarium, Mucor, Simplicillium, Penicillium, Purpureocillium, Plectosphaerella and Cunninghamella. They were obtained from the screening of twelve weed-rhizosphere soil samples from a coal dump site and an unpolluted control zone. All the species identified in this study have been previously isolated from soil, namely Purpureocillium lilacinum [54], Plectosphaerella cucumerina [55], Fusarium oxysporum, Fusarium fujikuroi [56], Mucor circinelloides, Cunninghamella bertholletiae [57, 58], Aspergillus aculeatus, Aspergillus flavus, Aspergillus niger, Aspergillus oryzae, Penicillium citrinum, Penicillium daleae [59-61] Simplicillium subtropicum, Trichoderma asperellum and Trichoderma koningiopsis [62, 63].

Aspergillus flavus and Trichoderma asperellum were the most versatile having been recovered from four and three different rhizospheres, respectively. Among the cultivable fungi across the rhizospheres, Aspergillus was the dominant genus followed by Trichoderma. The most frequently occurring species identified from different rhizospheres were A. flavus, A. niger and P. griseofulvum, while there were single occurrences of $S$. subtropicum and $T$. reesei from the rhizospheres of $A$. compressus. and S. nodiflora, respectively.

Furthermore, the presence of $T$. koningiopsis, $C$. bertholletiae and S. subtropicum in the rhizospheres of E. coccinea, A. conyzoides and $A$. compressus, respectively, from the coal dumpsite is supported by a previous report in which a coal-degrading fungus, $N$. fischeri, was isolated from the root zone of Cynodon dactylon [39]. Moreover, it is plausible that the presence of these organisms may relate to the survival of these plants in the coal-polluted environment. This is in tandem with various studies that confirm that a correlation exists between root microflora and plants' capabilities for remediation [32, 39, 64].

The records on fungal degradation of sub-bituminous coal are inadequate in comparison with the numerous reports of the other low ranked coal, lignite. Biodegradation of coal by fungal species, first reported by Fakoussa [65] and subsequently by Cohen and Gabriele [23], led to a series of studies that demonstrated the ability of a range of microbial species that are able to catalyze this process $[19,23,66-69]$. Particularly, there have been no accompanying reports to the studies on the Penicillium simplicissimum-mediated solubilization of Nigerian subbituminous coal [34, 35].

\subsection{Coal activity assay}

Seventeen isolates, namely RCZ1D.4, RCZ2A.1, RCZ2B.2, RCZ2C.2, RCZ2D.2, RCZ2D.5, RIZ3.1, RIZ4.2, RIZ4.4, RIZ5.3, RIZ9.3, RIZ10.2, RCZ2B.1B, RCZ2B.2B, RCZ2B.3B, RIZ4.1B and $\mathrm{RIZ4.2B}$ showed good growth on $\mathrm{CAP}$, whereas scanty or no growth was observed on the control WAP (Fig. 1). Out of these 17 isolates, seven had the most mycelial growth in the liquid medium and were selected on the inference that more biomass should indicate the suitability of the fungus biodegradation studies (Fig. 2). They include RCZ2B.2, RCZ2B.2B, RCZ2D.2, RIZ3.1, RIZ4.2, RIZ5.3 and RIZ9.3.

The efficient growth rate of the seven fungal species, Aspergillus tubingensis, Mucor circinelloides, Cunninghamella bertholletiae, Simplicillium subtropicum, Penicillium daleae, Trichoderma koningiopsis and Purpureocillium lilacinum, on both CAP and CB could be explained by their capabilities to utilize coal as a nutrient source for their survival in the absence of other simple carbon sources. Some of the organisms from this study identified to be capable of bioconversion of coal and its derivatives have been frequently reported as being indigenous to the coal environment. They include organisms of the genera Penicillium, Mucor, Aspergillus, Cunninghamella and Trichoderma [22, 70-75].

\subsection{Evidence for humic acid and fulvic acid production}

For the coal activity testing, the control flask (without inoculum) had a $\mathrm{pH}$ of 5.69 , while the media for isolates RCZ2B.2, RIZ5.3, RIZ3.1, RCZ2D.2, RIZ9.3, RIZ 4.2 and RCZ2B.2B had pH values of $6.09,5.69,5.35,5.20,5.11,4.84$ and 4.50, respectively. For HA concentrations, RCZ2B.2B was the highest $(118.9 \mathrm{mg} / \mathrm{l})$ followed by RCZ2B.2 (43.9 mg/l) and RIZ5.3 (5.85 mg/l), RIZ3.1 (5.49 mg/l), RCZ2D.2 (5.00 mg/l), RIZ4.2 (3.29 mg/l) and RIZ9.3 $(2.80 \mathrm{mg} / \mathrm{l})$. Fulvic acid analyses showed high concentration values for RIZ9.3 (67.03 mg/l), RIZ4.2 (45.95 mg/l), RCZ2D.2 (42.70 mg/l) and RIZ3.1 (42.43 mg/l), but low values for RIZ5.3 $(5.95 \mathrm{mg} / \mathrm{l}), \mathrm{RCZ2B.2}(5.68 \mathrm{mg} / \mathrm{l})$ and RCZ2B.2B (2.97 mg/l) (Figs. 3 and 4).

Essentially, the chemical pretreatment of the sub-bituminous coal before the application of the fungal inoculum improved the solubilization rate of the HA obtained. A related study by Sabar et al. [76] also conducted both chemical and fungal treatment on sub-bituminous coal to obtain a good yield of HA. In this study, the coal activity of the biosolubilizers ( $M$. circinelloides and A. tubingensis) and depolymerizers (C. bertholletiae, S. subtropicum, 
Table 1 Fungal species isolated and GenBank accession numbers for their partial ITS sequences

\begin{tabular}{|c|c|c|c|c|c|}
\hline $\mathrm{S} / \mathrm{N}$ & Sample ID & Lab stock number & Probable ID & Source & GenBank accession No \\
\hline 1 & RCZ1D.1 & IYN17 & Aspergillus flavus & Synedrella nodiflora & MW260075 \\
\hline 2 & RCZ1D.2 & IYN18 & Trichoderma asperellum & & MW260076 \\
\hline 3 & RCZ1D.3 & IYN19 & Trichoderma asperellum & & MW260077 \\
\hline 4 & RCZ1D.4 & IYN20 & Trichoderma asperellum & & MW260078 \\
\hline 5 & RCZ2A.1 & IYN21 & Trichoderma asperellum & Ageratum conyzoides & MW260079 \\
\hline 6 & RCZ2A.2 & IYN22 & Trichoderma asperellum & & MW260080 \\
\hline 7 & RCZ2A.3 & IYN23 & Trichoderma asperellum & & MW260081 \\
\hline 8 & RCZ2A.4 & IYN24 & Trichoderma asperellum & & MW260082 \\
\hline 9 & RCZ2B.1 & IYN25 & Fusarium oxysporum & Emilia coccinea & MW260083 \\
\hline 10 & RCZ2B.1B & IYN2 & Aspergillus flavus & & MW260071 \\
\hline 11 & $\mathrm{RCZ2B} .1 \mathrm{~S}$ & IYN6 & Aspergillus flavus & & MW250191 \\
\hline 12 & RCZ2B.2 & IYN26 & Aspergillus tubingensis & & MW260084 \\
\hline 13 & $\mathrm{RCZ2B} .2 \mathrm{~B}$ & IYN13 & Mucor circinelloides & & MT421897 [85] \\
\hline 14 & $\mathrm{RCZ2B} .2 \mathrm{~S}$ & IYN7 & Aspergillus aculeatus & & MW250192 \\
\hline 15 & RCZ2B.3 & 1YN27 & Mucor circinelloides & & MW260085 \\
\hline 16 & $\mathrm{RCZ2B} .3 \mathrm{~B}$ & IYN3 & Aspergillus flavus & & MW260072 \\
\hline 17 & RCZ2B.4 & IYN28 & Fusarium oxysporum & & MW260086 \\
\hline 18 & RCZ2C.1 & IYN29 & Aspergillus flavus & Urena lobata & MW260087 \\
\hline 19 & RCZ2C.2 & IYN30 & Aspergillus oryzae & & MW260088 \\
\hline 20 & RCZ2C.3 & IYN31 & Aspergillus oryzae & & MW260089 \\
\hline 21 & RCZ2C.4 & IYN32 & Fusarium sp. & & MW260090 \\
\hline 22 & RCZ2D.1 & IYN33 & Penicillium sp. & Axonopus compressus & MW260091 \\
\hline 23 & RCZ2D.2 & IYN34 & Penicillium daleae & & MW260092 \\
\hline 24 & RCZ2D.3 & IYN35 & Penicillium citrinum & & MW260093 \\
\hline 25 & RCZ2D.4 & IYN36 & Penicillium $s p$. & & MW260094 \\
\hline 26 & RCZ2D.5 & IYN37 & Aspergillus sp. & & MW260095 \\
\hline 27 & RCZ2D.S & IYN8 & Aspergillus oryzae & & MW250193 \\
\hline 28 & RIZ3.1 & IYN38 & Trichoderma koningiopsis & Emilia coccinea & MW260096 \\
\hline 29 & $\mathrm{RIZ3.2}$ & IYN39 & Aspergillus sp. & & MW260097 \\
\hline 30 & RIZ3.3 & IYN40 & Trichoderma koningiopsis & & MW260098 \\
\hline 31 & RIZ3.4 & IYN41 & Penicillium griseofulvum & & MW260099 \\
\hline 32 & RIZ3.5 & IYN42 & Aspergillus sp. & & MW260100 \\
\hline 33 & RIZ3.6 & IYN43 & Aspergillus niger & & MW260101 \\
\hline 34 & $\mathrm{RIZ4.1}$ & IYN44 & Penicillium griseofulvum & Axonopus compressus & MW260102 \\
\hline 35 & RIZ4.1B & IYN4 & Aspergillus aculeatus & & MW260073 \\
\hline 36 & RIZ4.2 & IYN45 & Simplicillium subtropicum & & MW260103 \\
\hline 37 & RIZ4.2B & IYN5 & Aspergillus flavus & & MW260074 \\
\hline 38 & RIZ4.3 & IYN46 & Penicillium griseofulvum & & MW260104 \\
\hline 39 & RIZ4.4 & IYN47 & Purpureocillium lilacinum & & MW260105 \\
\hline 40 & RIZ4.5 & IYN48 & Purpureocillium lilacinum & & MW260106 \\
\hline 41 & RIZ5.1 & IYN49 & Aspergillus niger & Synedrella nodiflora & MW260107 \\
\hline 42 & $\mathrm{RIZ5.2}$ & IYN50 & Fusarium fujikuroi & & MW260108 \\
\hline 43 & RIZ5.3 & IYN51 & Purpureocillium lilacinum & & MW260109 \\
\hline 45 & RIZ5.5 & IYN15 & Trichoderma reesei & Synedrella nodiflora & MT421898 [85] \\
\hline 46 & RIZ8B.S & IYN9 & Fusarium oxysporum & Ageratum conyzoides & MW250194 \\
\hline 47 & RIZ9.1 & IYN53 & Aspergillus niger & Ageratum conyzoides & MW260111 \\
\hline 48 & RIZ9.2 & IYN54 & Aspergillus niger & & MW260112 \\
\hline 49 & RIZ9.3 & IYN55 & Cunninghamella bertholletiae & & MW260113 \\
\hline 50 & RIZ9.4 & IYN56 & Cunninghamella bertholletiae & & MW260114 \\
\hline 51 & RIZ9.S & IYN10 & Aspergillus niger & & MW250195 \\
\hline
\end{tabular}

SN Applied Sciences 
Table 1 (continued)

\begin{tabular}{|c|c|c|c|c|c|}
\hline $\mathrm{S} / \mathrm{N}$ & Sample ID & Lab stock number & Probable ID & Source & GenBank accession No \\
\hline 52 & RIZ10.1 & IYN57 & Fusarium sp. & Ageratum conyzoides & MW260115 \\
\hline 53 & RIZ10.2 & IYN58 & Fusarium oxysporum & & MW260116 \\
\hline 54 & RIZ10.3 & IYN59 & Penicillium griseofulvum & & MW260117 \\
\hline 55 & RIZ10.4 & IYN60 & Fusarium oxysporum & & MW260118 \\
\hline 56 & RIZ10.5 & IYN61 & Fusarium solani-melongenae & & MW260119 \\
\hline 57 & RIZ10.6 & IYN62 & Fusarium fujikuroi & & MW260120 \\
\hline 58 & RIZ11.1S & IYN11 & Aspergillus flavus & Sida acuta & MW250196 \\
\hline 59 & RIZ11.2S & IYN12 & Aspergillus niger & & MW250197 \\
\hline 60 & RIZ11.3S & IYN14 & Trichoderma asperellum & & MW250198 \\
\hline 61 & RIZ11.4S & IYN16 & Aspergillus sp. & & MW250199 \\
\hline
\end{tabular}

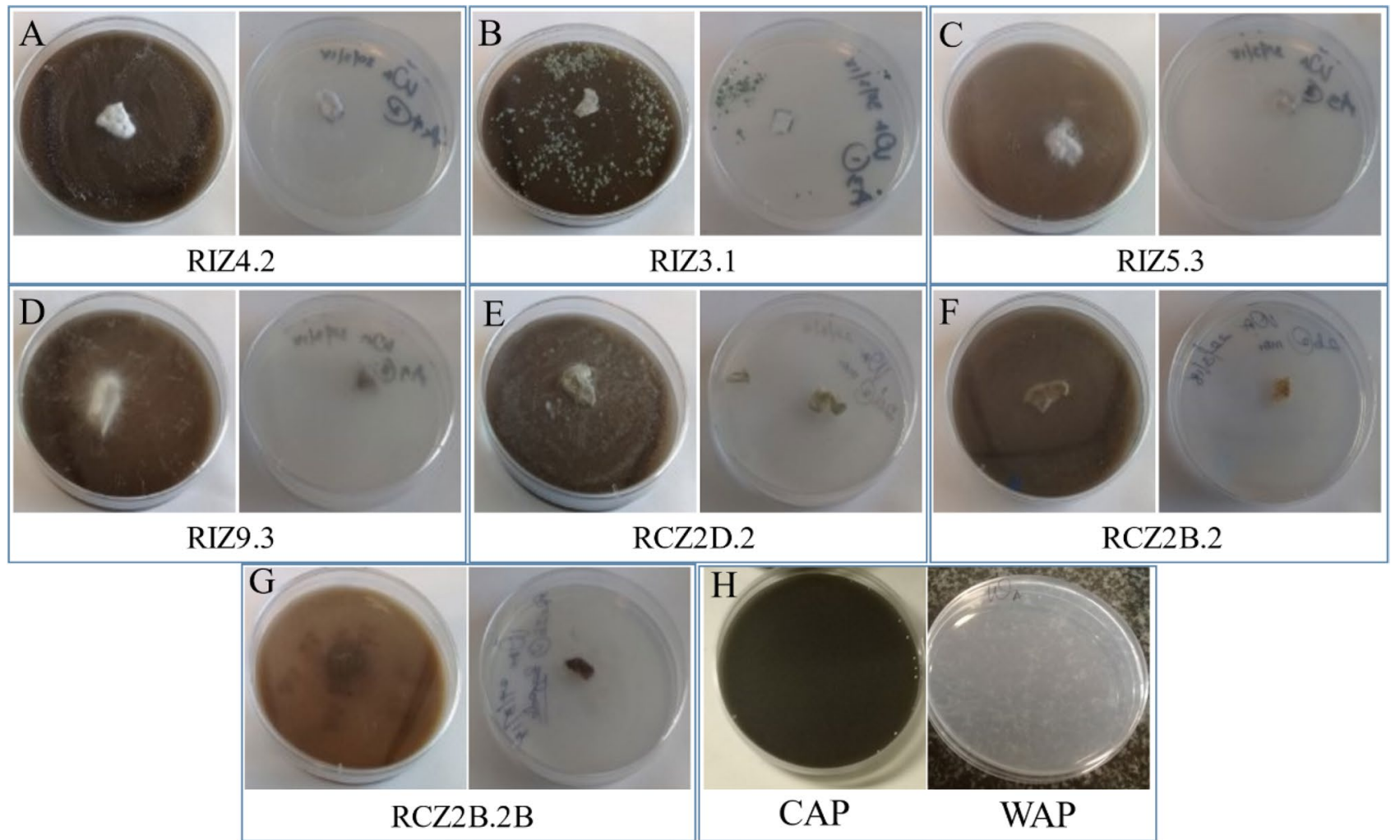

Fig. 1 Representative plates of fungal activity on coal agar plates (CAP) (left) and water agar plates (WAP) (right) and the plant rhizospheres from which they were isolated A RIZ4.2 (Axonopus compressus). B RIZ3.1 (Emilia coccinea). C RIZ5.3 (Synedrella nodiflora). D

P. daleae and T. koningiopsis) signified the potential of these organisms for bioconversion of coal to value-added products. If $\mathrm{HA}$ is depolymerized to $\mathrm{FA}$, a reverse order in concentration is expected to confirm bioconversion capabilities of the strains. In our investigation, a corresponding increase in FA concentration was noted in the media with a decreased HA concentration in C. bertholletiae $(\mathrm{HA}=2.80 \mathrm{mg} / \mathrm{l}, \mathrm{FA}=67.03 \mathrm{mg} / \mathrm{l})$, S. subtropicum
RIZ9.3 (Ageratum conyzoides). E RCZ2D.2 (Axonopus compressus). F RCZ2B.2 from Emilia coccinea. G RCZ2B.2B (Emilia coccinea). H Uninoculated coal agar plate (CAP) and water agar plate (WAP)

( $\mathrm{HA}=3.29 \mathrm{mg} / \mathrm{l}, \mathrm{FA}=45.95 \mathrm{mg} / \mathrm{l})$, P. daleae $(\mathrm{HA}=5.00 \mathrm{mg} / \mathrm{l}$, $\mathrm{FA}=42.70 \mathrm{mg} / \mathrm{l}$ ) and T. koningiopsis ( $\mathrm{HA}=5.49 \mathrm{mg} / \mathrm{l}$, $\mathrm{FA}=42.43 \mathrm{mg} / \mathrm{l})$. On the other hand, P. lilacinum recorded low amounts of both HA as well as FA and could not convert the bulk of the coal as evident by the deep black coloration of the medium. P. daleae was the only depolymerizer isolated from the control zone, while all other strains with a higher concentration of FA were isolated from the 


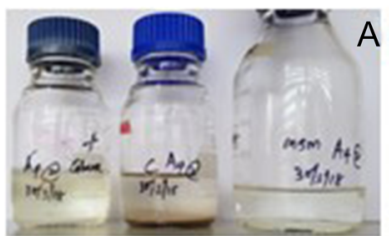

$\mathrm{RIZ4.2}$

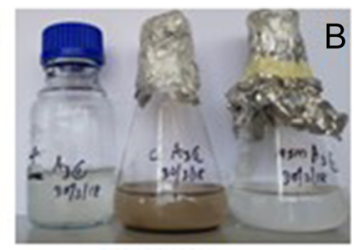

RIZ3.1

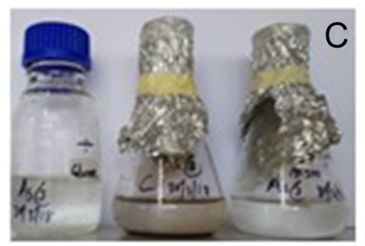

$\mathrm{RIZ5.3}$

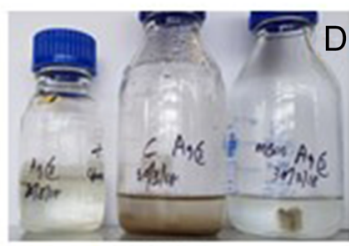

RIZ9.3

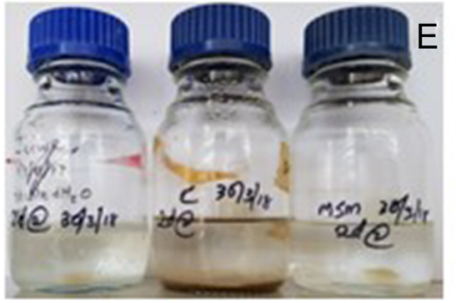

RCZ2D.2

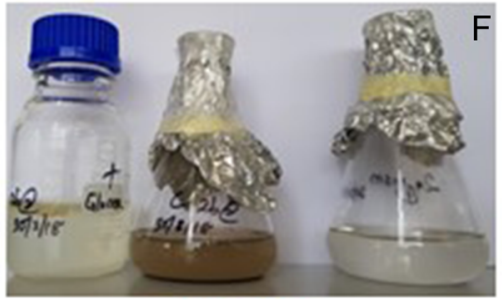

RCZ2B.2

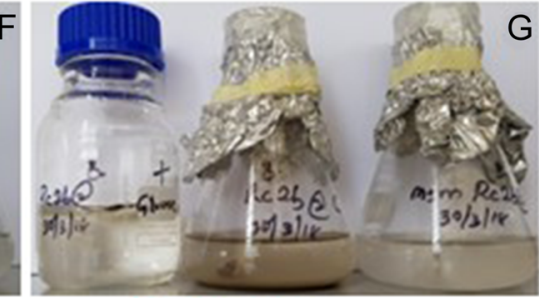

RCZ2B.2B

Fig. 2 Fungal activity in glucose broth (positive control), sub- bituminous coal medium and minimal salts medium (MSM) (negative control). A RIZ4.2, B RIZ3.1, C RIZ5.3, D RIZ9.3, E RCZ2D.2, F RCZ2B.2, G RCZ2B.2B
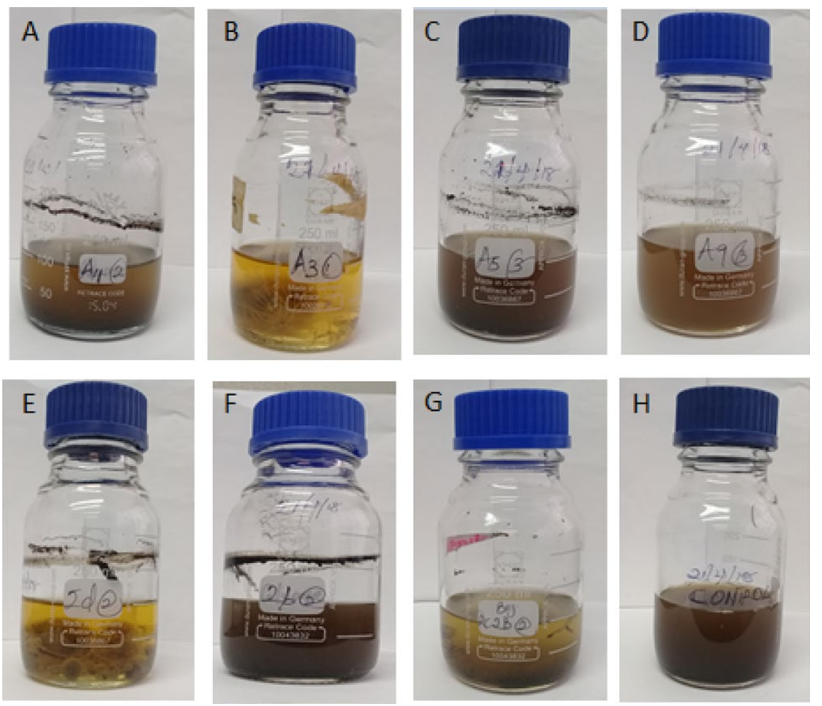

Fig. 3 Biosolubilization activity of seven most active strains. A RIZ4.2 (Axonopus compressus). B RIZ3.1 (Emilia coccinea). C RIZ5.3 (Synedrella nodiflora). D RIZ9.3 from (Ageratum conyzoides). E RCZ2D.2 (Axonopus compressus). F RCZ2B.2 (Emilia coccinea). G RCZ2B.2B (Emilia coccinea). $\mathbf{H}$ Control

coal dump site. The best solubilizer, Mucor circinelloides, was also isolated from the control zone.

The $\mathrm{pH}$ values of the controls were unchanged after solubilization. The $\mathrm{pH}$ of the medium inoculated with Aspergillus tubingensis increased, and this is most likely due to the secretion of alkaline substances, a requirement for the effective solubilization of coal and its derivatives [77,

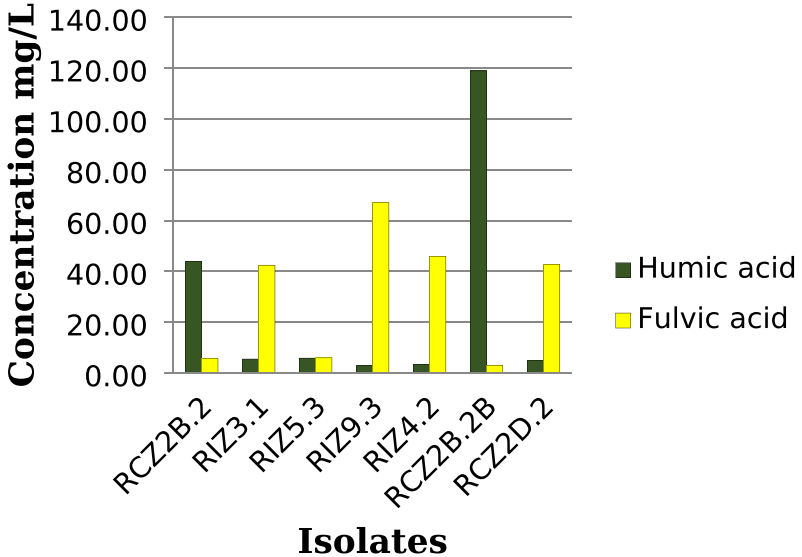

Fig. 4 Amounts of humic acid and fulvic acid produced by the seven candidate coal degraders due to biosolubilization and depolymerization, respectively

78]. There was a decrease in the $\mathrm{pH}$ of all other inoculated media with a maximum reduction in $\mathrm{pH}$ from 5.69 to 4.50 in M. circinelloides. In the other flasks with a decreased $\mathrm{pH}$, other mechanisms apart from increasing alkalinity might be responsible for the coal solubilization by these microbes [68]. One of which is that the increased acidity in the broth could be attributed to the formation of acidic metabolites during the conversion process. In line with the above findings, Quigley et al. [79] reported a direct relationship between alkaline solubility and biosolubilization of lignite, whereby the $\mathrm{pH}$ of the alkaline buffer was found to have decreased from its original value due 
to the formation of acidic compounds during coal solubilization. In another related study on the solubilization of Neyveli lignite by Aspergillus fumigatus and Fusarium udum into HA, Tripathi et al. [74] documented a reduction in $\mathrm{pH}$ from 7.5 to 6.0; an increase in acidity in the medium had the maximum yield of HA. It has been reported that coal solubilization precedes depolymerization of the released HA to FA [80].

\subsection{Molecular identification, phylogenetic and taxonomic analyses of isolates}

An amplicon size of 500-600 bp representing the ITS 1 and 2 regions of the fungal isolates was observed (Fig. S3). The isolates identified in this study either belong to the Ascomycetes or Zygomycetes, and their corresponding ITS sequences have been deposited in NCBI GenBank under various accession numbers MW260071-MW260120, MW250191, MT421897 and MT421898 (Table 1). The isolates used for biotransformation experiments were determined to be RCZ2B.2 (Aspergillus tubingensis), RCZ2B.2B/ IYN 13 (Mucor circinelloides), RCZ2D.2 (Penicillium daleae), RIZ3.1 (Trichoderma koningiopsis), RIZ4.2 (Simplicillium subtropicum), RIZ5.3 (Purpureocillium lilacinum) and RIZ9.3 (Cunninghamella bertholletiae) (Table 1).

The phylogenetic relationship among the coal solubilizers was plotted, and the isolates with coal utilization attributes were members of Ascomycota and Zygomycota and each formed a clade of its own (Fig. 5, Table 1).

\subsubsection{Amplification of laccase gene}

Laccase gene was amplified in all the depolymerizers Trichoderma koningiopsis (RIZ3.1), Penicillium daleae (RCZ2D.2), Simplicillium subtropicum (RIZ4.2) and Purpureocillium lilacinum (RIZ5.3) except Cunninghamella bertholletiae (RIZ9.3). Conversely, laccase gene was not amplified in the solubilizers, Aspergillus tubingensis and Mucor circinelloides.

The amplification of laccase gene in $T$. koningiopsis, $P$. daleae and S. subtropicum indicates that its presence in these strains is suggestive of a role for laccase in their depolymerization of humic acid. It was therefore not surprising that strains with higher FA and lower HA were found to have laccase, hinting that the enzyme might be responsible for catalyzing the depolymerization of $\mathrm{HA}$ to FA. The absence of laccase gene in C. bertholletiae (RIZ9.3) was expected as laccase activity has not been found in the species [81, 82]. From our findings, it appears that the depolymerization observed is not solely linked to laccase activity. C. bertholletiae might be employing another oxidative/ligninolytic enzyme other than laccase for its depolymerization activity. Similarly, the absence of laccase in the two efficient biosolubilizers from this investigation, $A$. tubingensis and $M$. circinelloides, could imply the exploitation of another ligninase or that a lignin-modifying enzyme might not be required for the process.

\section{Conclusion}

The culture methods of isolation of the fungi from soils in the root zone of the plants employed in this study are limited. Essentially, they provided a peek into the types of microorganisms in the rhizospheres of these plants but appreciably, an immense number of fungi would have been missed during cultivation. To obtain a comprehensive overview of the fungi present and how they relate in driving the metabolic activities, it would be necessary to investigate the full identities of the members of the fungal communities in this environment and their structure in the rhizosphere soils using the omics approaches. It will also be important to understand other enzyme mechanisms, in addition to laccase that aid these identified fungi from the Ascomycetes and Zygomycetes in their catalysis of coal biotransformation.

The following sub-bituminous coal biodegraders Aspergillus tubingensis, Mucor circinelloides, Simplicillium subtropicum, Penicillium daleae, Trichoderma koningiopsis and Cunninghamella bertholletiae were identified in this study. These isolates can be assembled to form a biocatalytic consortium for degradation of sub-bituminous coal to value-added products in the environment as well as in agro-industrial projects. In general, both humic acid and fulvic acid have agricultural roles and medicinal uses. Therefore, sub-bituminous coal could serve as a valuable raw material for the extraction of humic acid for the production of value-added products like ceramic dispersants [83] and as a soil conditioner [84]. 
Fig. 5 Neighbor-joining phylogenetic tree of ten representative OTUs of the isolates with coal activity and their relatives. Branches corresponding to partitions reproduced in less than $50 \%$ bootstrap replicates are collapsed. The percentage of replicate trees in which the associated taxa clustered together in the bootstrap test (1000 replicates) is shown next to the branches. The evolutionary distances were computed using the maximum composite likelihood method and are in the units of the number of base substitutions per site. This analysis involved 61 nucleotide sequences. Codon positions included were $1 s t+2 n d+3 r d+$ Noncoding. All ambiguous positions were removed for each sequence pair (pairwise deletion option). There was a total of 154 positions in the final dataset. Evolutionary analyses were conducted in MEGA X

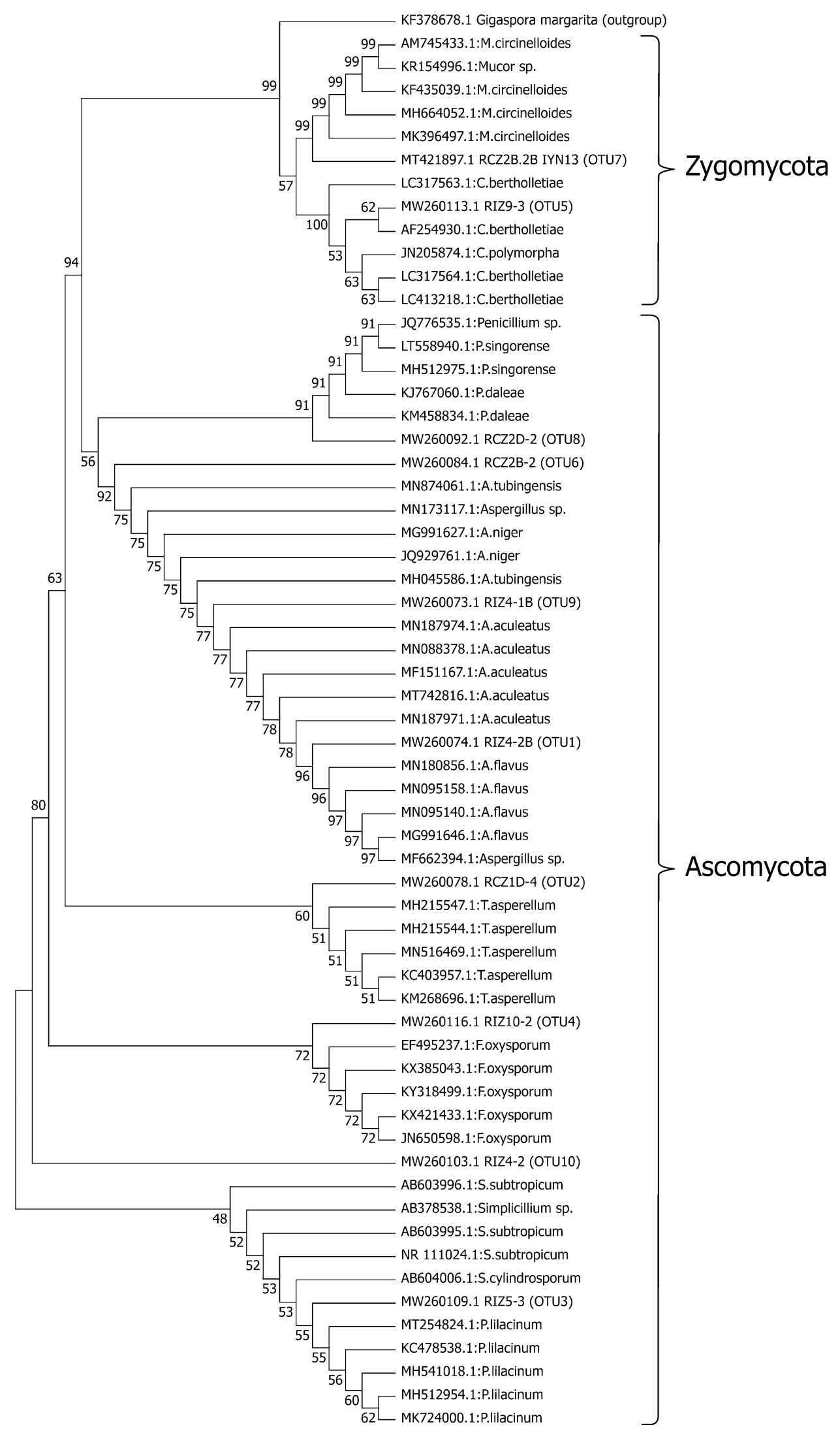


Acknowledgements We thank Dr. Nwanneka Marie Akinyemi and Mr, Ayodeji Adebola Odunsi of the Department of Microbiology, University of Lagos, for their participation in the studies. We also express our immense gratitude to the Agricultural Research Council (ARC)—Soil, Climate and Water, South Africa, for unhindered access to laboratory facilities during this research as well as to the members of its Environmental Microbiology and Biotechnology Research Group for all the assistance provided.

Authors' contributions Conceptualization was done by Imade Yolanda Nsa and Eric Egbe Igbinigie; Methodology was done by Imade Y. Nsa, Busayo Tosin Akinyemi, Maryam Bello-Akinosho, Eric Egbe Igbinigie and Rasheed Adegbola Adeleke; Formal analysis and investigation were carried out by Imade Yolanda Nsa, Busayo Tosin Akinyemi, Maryam Bello-Akinosho, Simon Nnamdi Ezechukwu, Tomisin Bridget Bayode, Eric Egbe Igbinigie and Rasheed Adegbola Adeleke; Writing - original draft preparation were done by Imade Yolanda Nsa, Busayo Tosin Akinyemi, Maryam Bello-Akinosho, Simon Nnamdi Ezechukwu, Tomisin Bridget Bayode, Eric Egbe Igbinigie and Rasheed Adegbola Adeleke; Writing - review and editing were done by Imade Yolanda Nsa, Maryam Bello-Akinosho, Eric Egbe Igbinigie and Rasheed Adegbola Adeleke, Funding acquisition was done by Imade Y. Nsa and Rasheed Adeleke; Resources were done by Imade Y. Nsa, Busayo Tosin Akinyemi, Maryam Bello-Akinosho, Simon Nnamdi Ezechukwu, Tomisin Bridget Bayode, Eric Egbe Igbinigie and Rasheed Adeleke; Supervision was done by Imade Yolanda Nsa, and Rasheed Adeleke.

\section{Declarations}

Conflict of interest The authors declare that they have no conflict of interest.

Open Access This article is licensed under a Creative Commons Attribution 4.0 International License, which permits use, sharing, adaptation, distribution and reproduction in any medium or format, as long as you give appropriate credit to the original author(s) and the source, provide a link to the Creative Commons licence, and indicate if changes were made. The images or other third party material in this article are included in the article's Creative Commons licence, unless indicated otherwise in a credit line to the material. If material is not included in the article's Creative Commons licence and your intended use is not permitted by statutory regulation or exceeds the permitted use, you will need to obtain permission directly from the copyright holder. To view a copy of this licence, visit http://creativecommons. org/licenses/by/4.0/.

\section{References}

1. Dhar BB (1993) Environmental scenario in Indian mining industry. In: Chaudhary RN, Shiv Kumar M (eds) Environmental management, geo water and engineering aspects. Balkema, Rotterdam, pp 615-619

2. International Energy Agency (2018) Market Report SeriesCoal 2018: Analysis and Forecasts to 2023. https://webstore. iea.org/market-report-series-coal-2018.

3. Younger PL (2004) Environmental impacts of coal mining of associated wastes: a geo-chemical perspective. Geol Soc 236:169-205
4. United States Energy Information Administration (2019) Coal and the environment. https://www.eia.gov/energyexplained/ index.php?page=coal_environment. Accessed 21 Jan 2019.

5. Sarma K (2005) Impact of coal mining on vegetation, a case study in Jaintia Hills district in Jaintia Hills, District of Meghalaya, India. A thesis. Submitted to the international institute for geo-information science and earth observation, Enschede, The Netherlands. pp 1-76.

6. Xiao W, Hu Z, Fu Y (2014) Zoning of land reclamation in coal mining area and new progresses for the past ten years. Int J Coal Sci Technol 1(2):177-183

7. Sarma K, Kushwaha SP, Singh KJ (2010) Impact of coal mining on plant diversity and tree population structure of Jaintia Hills district of Meghalaya, North east India. N Y Sci J 3(9):79-85

8. Ekka N, Behera N (2011) Species composition and diversity of vegetation developing on an age series of coal mine spoil in an open cast coal field in Orissa, India. Int Soc Trop Ecol 52(3):337-343

9. Cox WM (1988) Protocol for determining the best performing model. U.S. EPA, Office of Air Quality Planning and Standards, Research Triangle Park, North Carolina (June 1982). EPA, 1983, "Studies Related to Retention of Airborne Particulates in Coal Mine Pits-Data Collection Phase," Contract No. 68-03-3037, U.S. EPA, IERL, Cincinnati, Ohio (August 1983).

10. United States Environmental Protection Agency (2020). AP-42: Compilation of Air Emissions Factors. https://www.epa.gov/ air-emissions-factors-and-quantification/ap-42-compilationair-emissions-factors

11. Bowen, B.H. and Irwin, M.W. (2008). "Coal Mine Site Selection" CCTR Basic Facts File \#8, August. http://www.purdue.edu/dp/ energy/CCTR/outreach.php

12. Federal Republic of Nigeria, National Energy Policy (2003) Energy sources: Coal. pp 17-20

13. Fatoye FB, Gideon YB (2013) Appraisal of the economic geology of Nigerian coal resources. J Environ Earth Sci 3:25-31

14. Ezeigbo HI, Ezeanyim BM (1993) Environmental pollution from coal mining activities in the Enugu area Anambka state Nigeria. Mine Water Environ 12:53-61

15. Ogbonna P, Nzegbule E, Okorie $P$ (2015) Environmental Impact assessment of Coal mining at Enugu, Nigeria. Impact Assess Project Appraisal 33(1):73-70

16. Ralph JP, Catcheside DEA (1997) Transformations of low rank coal by Phanerochaete chrysosporium and other wood-rot fungi. Fuel Proces Technol 52:79-93

17. Steffen KT, Hatakka A, Hofrichter M (2002) Degradation of humic acids by litter decomposing basidiomycetes Collybia dryophila. Appl Environ Microbiol 68(7):3442-3448

18. Klein J, Catcheside DEA, Fakoussa R, Gazso L, Fritsche W, Höfer M, Laborda F, Margarit I, Rehm H-J, Reich-Walber M, Sand W, Schacht S, Schmiers H, Setti L, Steinbüchel A (1999) Biological processing of fossil fuels. Résumé of the Bioconversion Session of ICCS'97. Appl Microbiol Biotechnol 52:2-15

19. Igbinigie EE, Aktins $S$, van Breugel $Y$, van Dyke $S$, Davies- Coleman MT, Rose PD (2008) Fungal biodegradation of hard coal by a newly reported isolate, Neosartorya fischeri. Biotechnol J 3:1407-1416

20. Sekhohola LM, Isaacs ML, Cowan AK (2014) Fungal colonization and enzyme-mediated metabolism of waste coal by Neosartorya fischeri strain ECCN 84. Biosci Biotechnol Biochem 78(10):1797-1802

21. Sekhohola LM, Cowan AK (2017) Biological conversion of lowgrade coal discard to a humic substance-enriched soil-like material. Int J Coal Sci Technol 4(2):183-190 
22. Nsa I, Igbinigie E, Adeogun O, Adekunle A, llori O, Adongbede $M$ et al (2017) The potential of mycorrhizal associations of a coal dump site. J Ind Res Technol 6(1):165-177

23. Cohen MS, Gabriele PD (1982) Degradation of coal by the fungi Polyporus versicolor and Poria monticola. Appl Environ Microbiol 44:23-27

24. Catcheside DEA, Ralph JP (1999) Biological processing of coal. Appl Microbiol Biotechnol 5:16-24

25. Piccolo A, Spaccini R, Nieder R (2004) Sequestration of a biologically labile organic carbon in soils by humified organic matter. Clim Change 67(2-3):329-343

26. Trevisan S, Francioso O, Quaggiottil S, Nardi S (2010) Humic substances biological activity at the plant-soil interface from environmental aspects to molecular factors. Plant Sig Behav 5(6):635-643

27. Grinhut $T$, Hadar $Y$, Chen $Y$ (2007) Degradation and transformation of humic substances by saprotrophic fungi: processes and mechanisms. Fungal Biol Rev 21:179-189

28. Pettit RE (2008) Organic matter, humus, humate, humic acid, fulvic acid and humin: their importance in soil fertility and plant health. In: Conference proceedings: Allen institute for artificial intelligence, pp 1-17

29. Novák J, Kozler J, Janoš P, Čežiková J, Tokarová V (2001) Humic acids from coal of the North-Bohemian coal field I. Preparation and characterization. React Funct Polym 47:101-109

30. Janoš $P(2003)$ Separation methods in the chemistry of humic substances. J Chromatogr A 983:1-18

31. Hofrichter M, Fakoussa RM (2004) Microbial degradation and modification of coal. In: Steinbüchel A (ed) Lignin, humic substances and coal. Wiley, Weinheim, pp 393-425

32. Sekhohola L, Igbinigie E, Cowan A (2013) Biological degradation and solubilization of coal. Biodegradation 24:305-318

33. Kumar A, Chandra R (2020) Lignolytic waste and its mechanisms for lignocellulosic waste in the environment. Heliyon 6:2020

34. Achi OK, Emeruwa OC (1993) Influence of Cultural Conditions on Coal Solubilization by Penicillium simplicissimum. J Chem Tech Biotechnol 57:121-125

35. Achi OK (1994) Characterization of the intermediate product of coal solubilization by Penicillium simplicissimum. J Chem Tech Biotechnol 61:325-330

36. Sabar MA, Ali MI, Fatima N, Malik AY, Jamal A, Liaquat R, Hed $H$, Liud F, Guoe H, Urynowicz M, Huang Z (2020) Evaluation of humic acids produced from Pakistani subbituminous coal by chemical and fungal treatments. Fuel 278:118301. https://doi. org/10.1016/j.fuel.2020.118301

37. Olawale JT, Edeki OG, Cowan AK (2020) Bacterial degradation of coal discard and geologically weathered coal. Int J Coal Sci Technol 7:405-416. https://doi.org/10.1007/s40789-020-00306-3

38. Nsa IY, Oyebanji OO, Egbe EE, Odunsi AA (2021) Floristic distribution of a sub-bituminous coal dumpsite in Enugu, Nigeria. Front Ecol Evol. https://doi.org/10.3389/fevo2021.649954

39. Igbinigie EE, Mutambanengwe CZ, Rose PD (2010) Phyto-bioconversion of hard coal in the Cynodon dactylon/coal rhizosphere. Biotechnol J 5:292-303

40. Machnikowska H, Pawelec K, Podgórska A (2002) Microbial degradation of low rank coals. Fuel Process Technol 77(78):17-23

41. Prakash P, Namasivayam KR, Niveditha N, Tejaswini VK (2010) Optimization of humic acid by Trichoderma viridi and its effect on sorghum plant. J Biopest 3(1):155-157

42. Fakoussa RM, Frost PJ (1999) In vivo-decolorization of coalderived humic acids by laccase-excreting fungus Trametes versicolor. Appl Microbiol Biotechnol 52:60-65

43. Ghabbour EA, Davies G (2009) Spectrophotometric analysis of fulvic acid solutions-A second look. Ann Environ Sci 3:131-138
44. White TJ, Bruns T, Lee S, Taylor JW (1990) Amplification and direct sequencing of fungal ribosomal RNA genes for phylogenetics. In: Innis MA, Gelfand DH, Sninsky JJ, White TJ (eds) PCR protocols: a guide to methods and applications. Academic Press Inc, New York, pp 315-322

45. Hall TA (1999) BioEdit: a user-friendly biological sequence alignment editor and analysis program for Windows 95/98/NT. Nucleic Acids Symp Ser 41:95-98

46. Altschul SF, Gish W, Miller W, Myers EW, Lipman DJ (1990) Basic local alignment search tool. J Mol Biol 215:403-410

47. Katoh K, Standley DM (2013) MAFFT multiple sequence alignment software version 7: improvements in performance and usability. Mol Biol Evol 30(4):772-780

48. Saitou N, Nei M (1987) The neighbor-joining method: A new method for reconstructing phylogenetic trees. Mol Biol Evol 4:406-425

49. Kumar S, Stecher G, Li M, Knyaz C, Tamura K (2018) MEGA X: molecular evolutionary genetics analysis across computing platforms. Mol Biol Evol 35:1547-1549

50. Tamura K, Nei M, Kumar S (2004) Prospects for inferring very large phylogenies by using the neighbor-joining method. Proc Natl Acad Sci (USA) 101:11030-11035

51. Felsenstein J (1985) Confidence limits on phylogenies: An approach using the bootstrap. Evolution 39:783-791

52. Baldrian $P$ (2006) Fungal laccases: occurrence and properties. FEMS Microbiol Rev 30:215-242

53. Huang WT, Tai R, Hseu RS, Huang CT (2011) Overexpression and characterization of a thermostable, $\mathrm{pH}$-stable and organic solvent-tolerant Ganoderma fornicatum laccase in Pichia pastoris. Process Biochem 46:1469-1474

54. Lan X, Zhang J, Zong ZF et al (2017) Evaluation of the biocontrol potential of Purpureocillium lilacinum QLP12 against Verticillium dahliae in eggplant. Biomed Res Int 2:1-8

55. Atkins SD, Clark IM, Sosnowska D, Hirsch PR, Kerry BR (2003) Detection and quantification of Plectosphaerella cucumerina, a potential biological control agent of potato cyst nematodes, by using conventional PCR, real-time PCR, selective media, and baiting. Appl Environ Microbiol 69:4788-4793

56. Saremi H, Saremi H (2013) Isolation of the most common Fusarium species and the effect of soil solarisation on main pathogenic species in different climatic zones of Iran. Eur J Plant Pathol 137:585-596

57. Tombo E, Waxa A, Ntwampe $S$ (2015) Isolation of an endophytic cyanide resistant fungus Cunninghamella bertholletiae from (Manihot esculenta) and cassava cultivated soil for environmental engineering applications. https://doi.org/10.15242// IIE.E1115047.

58. Ziaee A, Zia M, Bayat M, Hashemi J (2016) Identification of Mucorales isolates from soil using morphological and molecular methods. Curr Med Mycol 2(1):13-19. https://doi.org/10.18869/ acadpub.cmm.2.1.13

59. Khattak SU, Iqbal Z, Lutfullah G, Bacha N, Khan AA, Saeed M, Ali M (2014) Phytotoxic and herbicidal activities of Aspergillus and Penicillium species isolated from rhizosphere and Soil. Pak J Weed Sci Res 20:293-303

60. Aziz NH, Zainol N (2018) Isolation and identification of soil fungi isolates from forest soil for flooded soil recovery. In: IOP conference series: materials science and engineering, vol 342, pp 1-9

61. Cho HS, Hong SB, Go SJ (2005) First Report of Penicillium brasilianum and $P$. daleae Isolated from Soil in Korea. Mycobiology 33(2):113-117. https://doi.org/10.4489/MYCO.2005.33.2.113

62. Nonaka K, Kaifuchi S, Ōmura S, Masuma R (2013) Five new Simplicillium species (Cordycipitaceae) from soils in Tokyo, Japan. Mycoscience 54:42-53 
63. du Plessis IL, Druzhinina IS, Atanasova L, Yarden O, Jacobs K (2018) The diversity of Trichoderma species from soil in South Africa with five new additions. Mycologia 110:559-583

64. Mukasa-Mugerwa TT, Dames JF, Rose PD (2011) The role of a plant/fungal consortium in the degradation of bituminous hard coal. Biodegradation 22:129-141

65. Fakoussa RM (1981) Kohle als Substrat für Mikroorganismen: Untersuchungen zur mikrobiellen Umsetzung native Steinkohle. Ph.D. Dissertation, Universita"t Bonn, Bonn. Translated as: Coal as a substrate for microorganisms: investigations of the microbial decomposition of untreated hard coal. Prepared for USDepartment of Energy, Pittsburgh. Energy Technology Centre.

66. Catcheside DEA, Ralph JP (1998) Biological processing of coal. Appl Biochem Biotechnol 52:16-24

67. Cohen MS, Feldman KA, Brown CS, Gray ET Jr (1990) Isolation and identification of the coal-solubilizing agent produced by Trametes versicolor. Appl Environ Microbiol 56:3285-3291

68. Fakoussa RM, Hofrichter M (1999) Biotechnology and Microbiology of coal degradation. Appl Microbiol Biotechnol 52:25-40

69. Cowan AK, Lodewijks HM, Sekhohola LM, Edeki OG (2016) In situ bioremediation of South African coal discard dumps. In: Fourie $A B$, Tibbett $M$ (eds) Proceedings, Mine Closure. Australian Centre for Geomechanics, Perth, pp 501-509

70. Scott CD, Strandberg GW, Lewis SN (1986) Microbial solubilization of coal. Biotechnol Prog 2:131-139

71. Stewart DL, Thomas BL, Bean RM, Fredrickson JK (1990) Colonization and degradation of oxidized bituminous and lignite coals by fungi. J Ind Microbiol Biotechnol 6:53-58

72. Laborda F, Monistrol IF, Luna N, Fernandez M (1999) Processes of liquefaction/solubilization of Spanish coals by microorganisms. Appl Microbiol Biotechnol 52:49-56

73. Hölker U, Schmiers H, Grosse S, Winkelhöfer M, Polsakiewicz M, Ludwig S, Dohse J, Höfer M (2002) Solubilization of low-rank coal by Trichoderma atroviride: evidence for the involvement of hydrolytic and oxidative enzymes by using 14C labelled lignite. $\mathrm{J}$ Ind Microbiol Biotechnol 28(4):207-212

74. Tripathi RC, Jain VK, Tripathi PSM (2009) Fungal biosolubilization of Neyveli lignite into humic acid, part A: recovery, utilization, and environmental effects. Energy Sources 32(1):72-82

75. Ghani MJ, Rajoka MI, Kalsoom A (2015) Investigations in fungal solubilization of coal: mechanisms and significance. Biotechnol Bioprocess Eng 20:634-642

76. Sabar MA, Ali MI, Fatima N, Malik AY, Jamal A, Liaquat R, He H, Liu F-J, Guo H, Urynowicz M, Huang Z (2020) Evaluation of humic acids produced from Pakistani subbituminous coal by chemical and fungal treatments. Fuel 278:118301. https://doi.org/10. 1016/j.fuel.2020.118301

77. Hofrichter M, Bublitz F, Fritsche W (1997) Fungal attack on coal II. Solubilization of low-rank coal by filamentous fungi. Fuel Process Technol 52:55-64

78. Hölker U, Ludwig S, Scheel T, Höfer M (1999) Mechanisms of coal solubilization by the deuteromycetes Trichoderma atroviride and Fusarium oxysporum. Appl Microbiol Biotechnol 52:57-59

79. Quigley DR, Ward B, Crawford DL, Hatcher HJ, Dugan PR (1989) Evidence that microbially produced alkaline materials are evolved in coal biosolubilization. Appl Biochem Biotechnol 20(21):753-763

80. Hofrichter M, Fritsche W (1997) Depolymerization of low rank coal by extracellular fungal enzymes systems. III. In vitro depolymerization of coal humic acids by a crude preparations of manganese peroxidase from the white rot fungus Nematoloma frowardii b19. Appl Microbiol Biotechnol 47(5):566-571

81. Bhosale S, Saratale G, Govindwar S (2006) Biotransformation enzymes in Cunninghamella blakesleeana (NCIM-687). J Basic Microbiol 46:444-448

82. Nguyen TT, Choi YJ, Lee HB (2017) Isolation and characterization of three unrecorded Zygomycete fungi in Korea: Cunninghamella bertholletiae, Cunninghamella echinulata, and Cunninghamella elegans. Mycobiology 45:318-326

83. de Souza F, Bragança SR (2017) Extraction and characterization of humic acid from coal for the application as dispersant of ceramic powders. J Mater Res Technol 7(3):254-260. https:// doi.org/10.1016/j.jmrt.2017.08.008

84. Fong S, Seng L, Nan C, Asing J, Md N, Pauzan A (2006) Characterization of the coal derived humic acids from Mukah, Sarawak as soil conditioner. J Braz Chem Soc. https://doi.org/10.1590/ S0103-50532006000300023

85. Nsa IY, Adeloye GB, Odunsi AA, Akinyemi BT, Tubonemi JT, Saliu MO, Adepoju JP (2020) FAMEs profile of oil produced by oleaginous fungi isolated from fermented beverage wastewaters and soil. Niger J Biotechnol 37(1):140-151

Publisher's Note Springer Nature remains neutral with regard to jurisdictional claims in published maps and institutional affiliations. 